\title{
Codicia sin límites y pecado estructural a la luz de la pobreza globalizada: relectura de categorías bíblicas en Santiago y Pablo ${ }^{1}$
}

Greed without Limits and Structural Sin in the Light of Globalized Poverty: Reading Biblical Categories in James and Paul

Avivamento Sem Limites e Pecados Estruturais à Luz da Pobreza

Globalizada: Re-leitura de Categorias Bíblicas em Santiago e Pablo

Elsa Tamez elsa.tamez@gmail.com Recibido: 06 de marzo 2017 Aprobado: 15 de mayo 2017

Mi conferencia la he dividido en dos partes. En la primera introduzco el tema de la pobreza de hoy, es decir los nuevos pobres y el sistema que los produce. En la segunda parte analizo desde la Biblia algunas categorías bíblicas en Santiago y en Pablo que nos ayudan a hacer una lectura teológica de la realidad que está produciendo esos nuevos pobres. Me voy a centrar en la

1 Conferencia, Bogotá Colombia.

volumen 10, Número 1,2016 SIXÔ ${ }^{\text {9 }} 15$ 


\section{SIXÔ ’ volumen 10, Números 1, 2016}

codicia, el pecado, la ley y la muerte. Termino con un llamado a cambiar de rumbo.

\section{Los nuevos pobres}

Hablar de pobres hoy, en tiempos de la globalización del mercado neoliberal, no es lo mismo que hablar de los pobres de hace 40 años. Los pobres de antaño eran diferentes. De joven a mí me gustaba leer Herman Hesse, y recuerdo que en su novela Damian a Sincler ${ }^{2}$, el personaje principal, le atemorizaba la existencia de un barrio pobre cercano a su casa, su familia le tenía prohibido acercarse a ese lugar. Para él, los pobres y el lugar de los pobres eran algo que le producía temor y fascinación a la vez. Yo era pobre en esos años ' 60 y me preguntaba: ¿Por qué será que nosotros los pobres les fascinamos a los niños ricos? Pensaba que era tal vez porque no teníamos que dormirnos a cierta hora como ellos estaban obligados a hacer, o porque jugábamos en la calle, descalzos, después de hacer las tareas de la escuela, (las casas eran pequeñas y no cabíamos), o porque no teníamos que lavarnos los dientes, no había pasta, ni estábamos obligados a comernos toda la comida ya que a duras penas alcanzaba para todos. No sé cuál era la fascinación, tal vez porque podíamos ensuciarnos sin que nos regañaran y mojarnos bajo la lluvia si queríamos. No lo sé. Pero lo que sí sé es que los pobres de nuestro mundo global causan mucho miedo, porque son vistos como delincuentes, criminales e ilegales, principalmente porque no tienen trabajo fijo. Ellos son los marginados, los que están al margen del sistema económico. Son aquellos que no tienen derecho a existir porque, como dice el filósofo Zygmunt Bauman, son "los consumidores frustrados". No ayudan a la economía porque no consumen, no compran. Bauman hace una interesante distinción entre la clase

2 Hermann Hesse, Damian a Sincler. 
trabajadora, la clase baja y los marginados. La clase trabajadora está integrada dentro del sistema, trabaja y recibe un salario; la clase baja también está integrada al sistema pues tiene la posibilidad de subir. Yo, en aquel tiempo, pertenecía a la clase baja, eso implicaba que podía ascender y salir de la pobreza. Hoy eso es casi imposible; la forma como funciona el sistema económico neoliberal hace que la clase baja se pase muy rápido al mundo de los marginados, de los excluidos, esos que se vuelven un problema para el mercado y la sociedad. Dentro de este tipo de marginados del mercado entran muchos grupos: los desempleados, los inmigrantes, los ilegales, las personas pobres con discapacidad, los indigentes, los jóvenes pandilleros, los ladrones, los drogadictos, entre otros. Es decir, todos los que no aportan a la economía a través del consumo. Por eso no es extraño que el desempleado sea visto como un criminal en potencia. Sabemos, según afirmaciones de economistas, que el sistema económico actual es incapaz de dar pleno empleo. Si el crecimiento económico se orienta más que todo, no en la productividad sino en el crecimiento financiero especulativo, y si la tecnología de punta está al servicio no de la producción del sustento, sino de los intereses económicos de los sectores que la financian, es de esperar que la clase trabajadora este en descenso. La clase baja que espera subir y progresar no suba, sino por el contrario, se siga engrosando por el descenso de la clase media y en lugar de subir baje a formar parte de los excluidos. De clase baja a sector marginado el límite es muy débil ¿Cuál es el pánico de la clase media?: perder el trabajo, bajar de estrato social y pasar a formar parte de los marginados ${ }^{3}$.

3 Tal vez algunos de ustedes se pregunten, pero ¿Cómo le hacen para vivir tantos desempleados? En América Latina el grueso de la población acude al subempleo, cada familia se la "rebusca" para vivir el día a día: vendiendo cosas, haciendo cosas, sirviendo en algo. Esto implica, sin embargo, que estos pobres están fuera de la cobertura de las prestaciones sociales, no tendrán pensión y las cosas se agravarán. 


\section{SIWÔ ${ }_{\text {volumen 10, Nuimerers 1, } 2016}$}

Esto no debiera ser así, y puede no ser así. Después de la crisis económica del 2008, economistas honestos están llamando la atención al problema del mercado de políticas neoliberales orientado por el interés propio. Se esperaba que un mercado libre, autoregulado, donde todos buscaran el propio interés iba, por arte de magia (la mano invisible de Adam Smith) a favorecer a todos. Pero no fue así, la desregulación del mercado no ha producido eso que se esperaba, al contrario, lo que ha producido son más pobres, excluidos y sobre todo una desigualdad social nunca antes vista en la historia. Por otro lado, un mercado sin reglas que lo restrinja, da rienda suelta a la codicia. Todos sabemos que mucho tuvo que ver la codicia de los banqueros en el rubro de la vivienda lo que hizo explotar la crisis económica. Hay una carencia ética que raya en lo cínico ${ }^{4}$.

Por eso hoy no se puede hablar de pobreza sin hablar de riqueza producida por la avidez de ganancia, inherente en las políticas del mercado desregulado. Sabemos, que el problema central está en que nuestro sistema de mercado capitalista de políticas neoliberales para que funcione debe centrarse en el lucro, la búsqueda máxima de ganancias, a menor costo y tiempo posible. Un sistema así, sin regulación de parte del Estado, produce lo que estamos viendo, una concentración de riqueza desproporcionada en unos pocos, que genera una desigualdad social también desproporcionada, más el desempleo y por consiguiente muchos excluidos. Desde hace ya tiempo que se está denunciando que la ética está en conflicto con la economía actual ${ }^{5}$. Las implicaciones son desbastadoras ${ }^{6}$ : violencia, guerras, criminali-

4 Cp. Musa Panti Filibus, "Justice Not Greed: Biblical Perspectives on Ethical Eficits of the Present Global Financial System" en Justice Not Greed, Eds. Pamela Brubaker y Rogate Mshana (Geneva: WCC Publications, 2010), pp. 45-59.

5 James M. Childs y Jr. Greed. Economics and Ethics in Conflict (Minneapolis: Fortress: 2000).

6 Cp. Joseph E. Stiglitz, The Price of Inequality: How Today's Divided society Endangers Our Future (W.W. Norton \& Company, Inc., 2012. (En español: El precio de la desigualdad. El 1\% de la población tiene lo que el 99\% necesita, (México: Taurus, 2012). 
dad; cárceles insuficientes y, además, una depredación del medio ambiente cuyas consecuencias estamos experimentando con el calentamiento global.

Lo bueno es que los economistas progresistas ya empezaron a reaccionar. Gracias a la crisis del 2008, el economista Premio Novel Paul Krugman dijo en una entrevista: "Este es uno de esos momentos en los cuales toda una filosofía ha sido desacreditada. Esos que defendieron que la codicia era una virtud y que los mercados deberían autoregularse, ahora sufren la catástrofe" 7 .

\section{Criterios bíblicos que orientan el discernimiento y las prácticas frente a la pobreza}

Yo no soy economista pero me doy cuenta que algo anda mal, como dice Tony Judt ${ }^{8}$ respecto de nuestro modelo económico. Si es verdad lo que dice el economista Premio Nobel Joseph E. Stiglitz de que el 1\% de la población tiene lo que el $99 \%{ }^{9}$ necesita, debería indignarnos. Yo soy biblista y como tal quiero referirme a unas categorías bíblicas que ofrecen criterios para discernir nuestra realidad económica y así podamos actuar orientados por estos criterios. Es verdad que las sociedades antiguas no eran tan complejas como las de ahora y que los tiempos son radicalmente diferentes, pero hay algunos principios que son válidos para frenar la avidez del lucro que produce tantos excluidos.

Para empezar, hay un principio bíblico que afirma que la codicia no es ninguna virtud, más bien es una condición humana que si se dan los mecanismos legales para que no tenga límites, se cae en el aniquilamiento del entorno natural y social. Hay

7 Paul Krugman, entrevisado por A. Gongales and M.'A Noced, El País, 15 de marzo de 2009, Sevilla.

8 Tony Judith, Algo anda mal (Bogotá: Taurus, 2010).

9 Joseph E Stiglitz, The Price..., 2012. 


\section{SIWÔ ${ }^{\text {volumen } 10, \text { Nimerers 1, 2016 }}$}

también una categoría teológica llamada pecado, que, si no se reduce a la moral sexual o a pecadillos, como se acostumbra en las iglesias, sino que se ve como un poder maligno esclavizante, puede servir como una herramienta de análisis de lo que pasa a nivel sistémico. Tenemos también la crítica paulina de la ley ${ }^{10}$, que, si no la reducimos a la ley de Moisés, se convierte en una valiosa categoría cuando la ley se hace cómplice del pecado.

Santiago habla de una trilogía: la codicia, el pecado y la muerte. Pablo habla de esta trilogía, pero la problematiza al añadir la ley, al pecado y la muerte. Voy a analizar estas categorías en ambos autores. Santiago, al utilizar el género sapiencial y profético, me ayuda a introducirme al mundo cotidiano de los pobres, y a su sufrimiento por la codicia de los ricos. Pablo, por su parte, con su análisis de la ley y el pecado en Romanos me ayuda a analizar la realidad económica. Esto es así porque con estas categorías se trasciende la codicia como condición humana, y al colocarla bajo el dominio del pecado legitimado por la ley, transforma la codicia en una codicia sin límites ${ }^{11}$, lo cual lleva a la muerte. Empecemos por Santiago.

\section{La codicia en Santiago}

Santiago es una carta escrita a migrantes que viven en Asia Menor (va dirigida "a las doce tribus de la dispersión"). A través de un análisis de la situación retórica observamos que son comunidades pobres que sufren hostilidad (Stg 1,2; 5,7-11) ${ }^{12}$ por parte de "los de afuera", porque son de otra etnia (son judíos),

10 Franz Hinkelammert, La maldición que pesa sobre la ley. Raíces del pensamiento crítico en Pablo de Tarso (San José: Ed. Arlekín, 2010).

11 Hinkelammert, La maldición que pesa sobre la ley. Raíces del pensamiento crítico en Pablo de Traso, p. 93.

12 Según Sophie Laws pueden estar pasando por fuertes problemas económicos y de persecución. The Epistle of James, Cambridge: Harper \& Row, 1980, p. 51. 
son migrantes, son pobres y siguen a otro Señor que no es el emperador. Dentro de la comunidad hay pobres que no tienen ropa para abrigarse del frío ni qué comer. $(2,15-16)$, les visitan indigentes $(1,2)$ y hay campesinos a quienes los terratenientes no les pagan su jornal, indispensable para vivir el día a día. A estos el autor de la carta les dice que aguanten, que no se dejen aplastar, les fortalece la esperanza diciendo que la situación va a cambiar. (1,2-4; 5,7-11). También hay comerciantes que buscan hacer negocio a gran escala.

Por otro lado, encontramos problemas al interior de la comunidad: falta de solidaridad con los más pobres. (Si un hermano o una hermana están desnudos y carecen del sustento diario, y alguno de vosotros les dice: «Idos en paz, calentaos y hartaos», pero no les dais lo necesario para el cuerpo, ¿de qué sirve? (Stg $2,15-16)$. Algunos se acomodan a los valores del patronazgo de la sociedad romana, rindiendo pleitesía a los ricos que le visitan en la comunidad $(2,2)$; otros, los comerciantes, solo piensan en la ganancia que obtendrán. (Ahora bien, vosotros los que decís: «Hoy o mañana iremos a tal ciudad, pasaremos allí el año, negociaremos y ganaremos» $[$ Stg 4,13$])$.

En el Nuevo Testamento el término griego epithymia, "deseo", aparece siempre en sentido negativo ${ }^{13}$, por eso puede traducirse como "codicia". Aparece en 1, 14-15 en el contexto de las tentaciones. Dios, dice, no tienta a nadie. Cada quien es tentado por el propio deseo o codicia. Es la codicia la que le arrastra a uno y le seduce. En el v. 15 tenemos una cadena de sucesos que representan las consecuencias de dejarse llevar por la propia codicia. Empieza con el adverbio "entonces" para comenzar a ilustrar los

13 Caso contrario a la LXX, donde aparece "el deseo" en su sentido neutro. Diccionario Exegético del Nuevo Testamento. Vol. I, Eds. Horst Balz y Gerhard Schneider, Traducido al español por Constantino Ruiz-Garrido (Salamanca: Sígueme, 1996), pp. 1501-1506. 


\section{SIWÔ ${ }^{\text {volumen } 10, \text { Nimerers 1, } 2016}$}

efectos de dejarse arrastrar por la codicia. El autor quiere unir deseo con pecado y con muerte, para ello utiliza una metáfora de reproducción sexual desde la seducción hasta el parto. En griego hay un paralelo propio de la retórica del autor entre concebir y consumar. Literalmente dice: "la codicia, habiendo concebido da a luz al pecado y el pecado habiendo sido consumado, engendra muerte". "Habiendo sido consumado", según Bauer (BDAG) puede conllevar el sentido figurado de "estar completamente formado". El sentido sería entonces que después que nace el pecado y se desarrolla completamente, da a luz la muerte.

¿Qué podría significar en Santiago en términos concretos? Podemos ilustrar esa cadena con dos pasajes. En el capítulo 4, aparece el deseo de tener; como los comerciantes o terratenientes no se satisfacen, se dejan arrastrar por ese deseo, hacen la guerra para conseguir lo que se quiere, con ello se comete pecado, se mata y todo conduce a la muerte. Veámoslo con más detalle.

En 4,1-10 se subraya "el tener". El autor pregunta: ¿De dónde procede la guerra, la violencia? Según él hay algo en el interior de las personas que busca pura satisfacción personal, puro interés propio, este deseo combate en el interior del ser. Dice Santiago: "Ustedes codician y no tienen, es decir, no les alcanza lo que quieren tener". Entonces asesinan porque tienen celos o envidía y aun así no les alcanza, no logran obtener lo que quieren. Entonces hacen la guerra, y no tienen lo que quieren. Y no lo piden (a Dios), y si lo piden, lo piden mal y no lo reciben, porque lo piden para gastarlo solo en sus placeres egoístas. A estos les llama "pecadores" en el v. 8, y les hace un llamado para que se "limpien las manos", es decir dejen los negocios sucios, y purifiquen sus corazones. Este es un llamado a la honestidad. Pero para ello tienen que frenar sus impulsos del corazón arrastrados por la codicia. Si lo hacen no usarían la violencia para conseguir lo que quieren, no pecarían y no habría muerte. 
Cualquiera podría decir que hay mucha retórica en estos versículos. Es verdad, la hay. Sin embargo, hay mucho de verdad. Eso lo podemos comprobar por lo que vemos ahora. Por ejemplo, sabemos que detrás de nuestras guerras, tanto civiles como entre países, el interés económico de los grupos o corporaciones (multinacionales) está a la cabeza. Todo lo demás es pretexto. Pero el versículo no está hablando solo de las guerras en relación con la codicia. Está hablando de una condición humana que exige poner límites. Si no hay límites a la codicia, las consecuencias pueden ser funestas.

Ahora bien, es importante tener claro que esta codicia que lleva a la violencia, que se explica por un deseo apasionado mal conducido de tener más y más, para satisfacer los deseos egoístas, es aplicable a las diferentes capas sociales. En el mundo de las favelas, donde se concentran los desplazados del campo y los excluidos del mercado laboral, la codicia se agudizada por el narcotráfico y va ganando terreno en la lucha por la sobrevivencia. Afirmar que la codicia es una virtud, es echar fuego a la situación insostenible que se vive en nuestro mundo global.

Volviendo a Santiago, el otro ejemplo lo encontramos en el capítulo 5, 1-7. Los terratenientes codiciosos quieren acumular riquezas, contratan campesinos, no les pagan el salario, con eso cometen pecado, matan de hambre al trabajador y Dios les anuncia su muerte. Los deseos desenfrenados y avaros se ven claramente en los terratenientes. En lenguaje apocalíptico el autor denuncia la acumulación de las riquezas, el oro, la plata y los vestidos lujosos, obtenidos gracias a la mano de obra de los campesinos. Por la avaricia el terrateniente no paga el jornal al agricultor. El salario retenido grita a Dios, lo mismo que el campesino explotado clama a Dios, denunciando la injusticia (ellos son los indignados del tiempo de Santiago); aquí tenemos la trilogía codicia, pecado y muerte, sin usar los términos. 
Ahora bien, el discurso de Santiago es bueno, pero como dijimos arriba, no es suficiente para un análisis de nuestra realidad dominada por un mercado orientado hacia la ganancia y que no admite regulaciones externas. Necesitamos otras categorías más vastas y complejas como las que encontramos en Pablo en Romanos. Pablo habla de otra trilogía además de la codicia: el pecado, la ley y la muerte.

\section{La codicia, el pecado, la ley y la muerte en Pablo}

Pareciera que en Santiago la situación puede cambiar si se pone freno a la codicia. Esto se logra a través del cumplimiento de la ley. Es importante aclarar que él tiene un concepto de ley diferente al de Pablo en Romanos. La ley para Santiago se reduce a la Torah, pero centrada en la ley del amor al prójimo, no tiene en mente ni los ritos cultuales ni la circuncisión. Para Santiago la ley es buena y amando al prójimo, es decir cumpliendo la ley regia $(2,8)$, la de la libertad $(2,12)$, se resuelve el problema de los pobres, la falta de solidaridad y la explotación. Pero hoy día esto no funciona. Apenas sería un paliativo, dejado a los pobres a merced de la compasión de la gente. Como dijimos arriba, tenemos un sistema económico desregulado, basado en el lucro y la codicia sin límites que es lo que produce la pobreza y el desempleo. Estamos hablando de pobreza y desempleo estructural ${ }^{14}$. Lo que busca el sistema económico actual no es la eliminación de la pobreza, es la acumulación de la riqueza y el aumento del consumo. Y lo que es peor, como dice el teólogo brasileño Jung Mo Sung, la eficiencia de la economía neoliberal se mide por la creación de deseos sin límites para el consumo infinito ${ }^{15}$. Mo Sung retoma de Girard la categoría del "deseo mimético", o sea,

14 Jung Mo Sung, Desejo, Mercado e Religião (Petrópolis: Vozes, 1998), p. 90.

15 Mo Sung, Desejo, Mercado e Religião, p. 55. 
el deseo de tener lo que los otros desean ${ }^{16}$ : el iPhone 5, el iPod, el iPad mini, entre otros. Todos estamos bajo ese sistema de economía de mercado libre, todos somos cómplices y víctimas. Los pobres no están exentos, hay pobres que, al ser seducidos por el deseo de tener un celular o tenis de marca, llegan a matar.

Por eso, para el análisis teológico de esa realidad actual que produce la pobreza y desigualdad tenemos que recurrir a Pablo. Vale aclarar que hoy no tenemos el problema de la ley mosaica ni de la circuncisión, problemas centrales en su discurso de la carta a los Romanos. Pero podemos releer la carta a la luz de otros problemas actuales, como la codicia, la inversión de los valores éticos, la exclusión provocada por el sistema económico, el rol y la manipulación de la ley.

Pablo, un viajero que conoce muchas ciudades greco-romanas donde el culto al emperador era una obligación; que ha estado frente a tribunales varias veces, que ha sufrido la cárcel, azotes, asaltos y otras tantas cosas que él llama las marcas del apóstol (2 Co 11, 23-27), conoce bien el contexto donde se mueve. Pablo no es ajeno al problema de los pobres ${ }^{17}$, aunque su discurso pareciera abstracto. Para él, detrás de la realidad de pobreza, explotación y violencia que se experimenta en tiempos del imperio romano hay un poder sistémico que potencializa esa condición natural humana: la codicia. Pablo llama pecado a este sistema. Para que funcione el sistema pecaminoso necesita de una ley, porque a través de ella funciona legítimamente, sin remordimiento de culpa. Esta crítica paulina de la ley la ha trabajado muy bien el economista Franz Hinkelamert. Para él

16 Mo Sung, Desejo, Mercado e Religião. p. 53.

17 El recordatorio que aparece en Gálatas 2.4, donde asume el compromiso de solidaridad con los pobres no es marginal en su misión, ni se reduce a la colecta que recoge entre los gentiles para los pobres de Jerusalén. Cp. Bruce E. Longenecker, Remember the Poor. Paul, Poverty, and the Greco-Roman World (Grand Rapids: William B. Eerdmans Publishing Co. 


\section{SIWÔ ${ }_{\text {volumen 10, Nuimerers 1, } 2016}$}

cuando Pablo habla de pecado no se trata de la violación de la ley, porque justamente el pecado, al valerse de la ley, produce "toda suerte de codicias", (Ro. 7, 8) ${ }^{18}$. Según Hinkelammert "se trata de la transformación de esta hambre natural (de cosas) en una codicia sin límites"19.

Pero vayamos más despacio. El tema central de Pablo en Romanos es la justica de Dios (dikaiosyne tou deou), pero antes de hablar de ella se ve obligado a analizar aquello que hace posible la manifestación de la justicia de Dios, es decir las prácticas de injusticia (adikia) que producen el pecado ${ }^{20}$. Pues bien, para entender el concepto de pecado en Pablo hay que tomar en cuenta que él utiliza el término en singular (amartia en griego). No está hablando de pecados (como robar, matar, entre otros) sino del pecado. Esto es fundamental para entender el argumento de que hace referencia a un poder oculto, sistémico, un fetiche. En Romanos 3,9, Pablo afirma que todos, tanto judíos como gentiles están bajo el pecado, y que no hay un justo, ni uno. Allí retoma las Escrituras y afirma que todos se han desviado: engañan, derraman sangre inocente, no conocen los caminos de la paz, entre otras cosas. Al decir que todos están bajo el pecado, Pablo personifica el pecado y lo ve como un poder que esclaviza a los humanos, de manera que, aunque quieran, no pueden hacer el bien. Esta situación les lleva a la muerte, ya que "la paga del pecado es la muerte" (Ro 6, 23). Nadie escapa de este poder, judíos y griegos, ricos y pobres, mujeres y hombres. Para Pablo es claro que quienes tienen la ley de Moisés también están sometidos al

18 El pecado dice Pablo en Romanos 7:8 “aprovechándose del mandamiento, produjo en mí toda codicia; porque sin la ley el pecado está muerto". (But sin, seizing an opportunity in the commandment, produced in me all kinds of covetousness. Apart from the law sin lies dead (7.8).

19 Hinkelammert, La maldición que pesa sobre la ley. Raíces del pensamiento crítico en Pablo de Tarso, p. 93.

20 Cp. Elsa Tamez, Contra toda condena. La justificación por la fe desde los excluidos (San José: DEI, 1990), en inglés: The Amnesty of Grace. 
pecado; están bajo su poder pues, aunque quieren seguir el mandamiento de no robar, roban (pues bien, tú que instruyes a los otros ¡a ti mismo no te instruyes! Predicas: ¡no robar!, y ¡robas! 2.21) ¿Cómo llegó Pablo a esta afirmación?

Primero que todo, es importante observar que no es sino hasta el capítulo 3.9 donde menciona el término pecado y en singular. Del capítulo 1 al 3 solamente habla de las prácticas de injusticia, tanto de los gentiles como de los judíos. Esto es importante tomar en cuenta porque antes de hablar de pecado, el apóstol Pablo debe dar contenido a lo que más tarde llamará pecado. Del capítulo uno al tres habla de las prácticas de injusticia; éstas serían aquellas mencionadas en Santiago, motivadas por la codicia. Ro (1, 29-32; 3,10-18). Pero, a diferencia de Santiago, Pablo habla de una inversión de valores en la medida en que estas prácticas de injusticia se multiplican legitimadas por la sociedad imperial romana. Las prácticas de injusticia se van invirtiendo y convirtiendo en prácticas justas y legales. Frente a esta sociedad invertida, la ira de Dios se desata. El versículo 1.18, lo anunció antes de desarrollar los temas de la justicia, el pecado y la ley. Dice Pablo: "La ira de Dios se revela desde el cielo contra toda impiedad e injusticia (adikia) de los hombres que detienen con injusticia la verdad". El versículo repite dos veces injusticia, y lo hace en sentido ético. Son las prácticas de injusticia las que aprisionan, retienen (katejont $n$ ) la verdad. En otras palabras, a lo injusto se le llama justo, a la mentira, verdad. En la literatura sapiencial se diría que en una sociedad invertida al malo le va bien y al bueno mal. Esta afirmación no es nada difícil ubicarla en el tiempo del imperio romano, cuando se llamaba salvador, señor, y humanísimo, al emperador; o cuando se le llamaba paz y seguridad a la ocupación militar de las tropas romanas en las provincias. La injusticia se postula como verdad y la justicia como mentira. Entonces, a partir del anuncio de la inversión de la sociedad, Pablo muestra cómo se fue dando la inversión. Tres veces 
menciona que en lugar de hacer esto..., ellos hicieron aquello ${ }^{21}$, por eso Dios los dejó a merced de sus actos. Ro (1, 23-28).

Pero, en el análisis de Pablo no se puede hablar de pecado sin hablar de ley ${ }^{22}$, pues como el mismo dice, el pecado está muerto sin la ley, el pecado cobra vida por la ley, y cuando se cumple la ley, se lleva a la muerte ${ }^{23}$. Por eso Pablo no tiene reparos en afirmar que el poder del pecado está en la ley (1 Co. 1,56). El capítulo 7 lo dedica a la participación de la ley en la manifestación del pecado. Allí observamos que el problema no es de la ley en sí, sola, ella es justa, es dada para que los humanos puedan convivir sin que se maten. El problema es la relación funesta del pecado y la ley. En 7, 10-11 Pablo escribe: Y hallé que el mismo mandamiento que era para vida, a mí me resultó para muerte, porque el pecado, aprovechándose del mandamiento, me engañó, y por él me mató.

Bajo un sistema pecaminoso, en el momento en que la persona se somete a la ley, su yo se aliena porque no interviene el discernimiento sino simplemente el cumplimiento ciego de la ley ${ }^{24}$. Por eso dice Pablo que, bajo la ley, sometida al pecado, uno hace lo que uno no quiere hacer, sino lo que uno odia $(7,15)$.

Sé que estos temas paulinos de la relación pecado-ley no son fáciles de comprender en una conferencia, pero voy a dar

21 Obsérvese el movimiento de inversión en el mismo discurso desde 1.19 hasta 3.9. En 1.23, 24 y 25, ellos cambiaron, invirtieron para mal la realidad y en los vs. 24, 26 y 28 Dios "los entregó", es decir, los "dejó a merced" de los "deseos codiciosos de su corazón" 24, "pasiones vergonzosas" 26, o "mente perversa" 28.

22 Pablo se refiere a la ley (nomos) en tanto norma inflexible que se impone para ser obedecida de forma ciega. Obviamente también podría entrar una interpretación de la torah (o de cualquier otra tradición religiosa) que exija una obediencia ciega. Esto es importante porque nos permite mantener la radicalidad de la crítica de Pablo a la ley sin que sea considerada una interpretación anti-semita.

23 El ejemplo máximo es Jesús de Nazaret crucificado legalmente por la ley, sin que nadie sienta culpa.

24 El pecado, la ley y los sujetos en Romanos 7.7-25. Un acercamiento hermenéutico. Conferencia dada en la reunión regional de SNTS, Bogotá, 2012. 
un ejemplo de la vida cotidiana de los excluidos, que nos ayuda a visualizar en forma concreta lo que parece abstracto sobre la relación ley-pecado:

Roberto fue a dar a la cárcel porque una cartera fue robada. Él es afrodescendiente y afirma no haber robado ninguna cartera. De todas maneras lo encierran en la prisión. La cartera aparece y Marcos, un mestizo, es llevado a la delegación de la policía. En el interrogatorio él señala que se vio obligado a robar porque necesitaba dinero para las medicinas de su hermana quien está muy enferma. Él dice que no se perdonaría si ella muere. Marcos reconoce su falta pero no encontró otra alternativa después que lo despidieron del trabajo cuando recortaron el personal. Roberto es liberado y sale furioso de la cárcel. El policía, conmovido, encierra con pesar a $\operatorname{Marcos}^{25}$.

Como estos casos hay miles, reflejan la relación común de los excluidos frente al pecado y la ley, en una sociedad clasista, racista y sexista. Si se analiza cada caso, se observa que la ley es buena y debe existir. Su funcionalidad, como se sabe, es que haya orden y se pueda convivir. Pero en la práctica cotidiana el cumplimiento de la ley no hace más que sacar a la luz la injusticia interhumana. Es fácil detectar que detrás de la ley hay un orden social construido de acuerdo a determinados intereses que benefician a cierto sector con poder y excluyen a muchos. Frente a ese orden económico, que se rige por sus leyes desreguladas, la ley legal y normativa resulta impotente en su deber de hacer justicia. Resulta, asimismo, manipulable. No son extraños los casos de asesinatos en los cuales, gracias a un abogado catalogado de bueno, el homicida queda libre. Hoy día, un buen abogado es aquel que defiende bien a su cliente independientemente de la culpabilidad.

25 Este es un ejemplo tomado de mi artículo: "El sistema pecaminoso, la ley y los sujetos en Romanos 7.7-25 en RIBLA 51 (2005). 


\section{SIWÔ ' volumen 10, Números 1, 2016}

\section{Conclusión: ¿Hay otra forma de vivir donde no haya empobrecidos?}

El análisis de Santiago y Pablo nos lleva a preguntarnos: ¿Es posible pensar y vivir de manera diferente?, ¿hay otras alternativas de vida posibles? Es interesante, los dos autores responden de manera diferente.

Santiago hace un llamado a la pureza de corazón, a dejar la codicia y avaricia, a ser solidarios con los pobres y a no discriminarlos. Cambiar de rumbo es posible para Santiago. Porque para Santiago no solo existe esta condición humana de la codicia, también afirma que Dios ha creado al ser humano por medio de "la palabra de verdad". En el versículo 18 el autor presenta una imagen femenina de Dios. El Padre que crea las luces del cielo (v 17), también "da a luz" a sus creaturas por el poder de su Palabra. Esta figura femenina de reproducción de la vida, se presenta como contraparte de la reproducción de la muerte en la trilogía que vimos arriba de codicia, pecado y muerte $(1,15)$. Se utiliza el mismo verbo griego para "dar a luz". El contraste es fuerte: mientras que el pecado da a luz la muerte, Dios, por su parte, da a luz la vida. Habría que entender "palabra de verdad" como palabra creadora o recreadora de la vida humana. En 1, 21 tenemos algo similar, el autor exhorta a que se deje la excesiva maldad y se reciba "la palabra implantada" (logos emphytos ${ }^{26}$ ) que es poderosa para salvar la vida. La exhortación a recibir la Palabra que ya ha sido sembrada tiene el poder de salvar porque libera de la codicia que lleva al pecado y a la muerte. Nacer por el poder de la palabra de verdad (1.18) y recibir la Palabra implantada (1, 21) funcionan como control de las tendencias negativas de la

26 Según Matt A, Jackson-McCabe el término logos emphytos era común entre los estoicos, para ellos sería la razón, el discernimiento como ley natural. Logos and Law in the Letter of James. The Law of Nature, the Law of Moses, and the Law of Freedom, (Atlanta: SBL, 2001), pp. 9-86. 
condición humana, y también como fuente de solidaridad con los pobres y los que sufren.

Pablo, en Romanos, va por otro lado, presenta el pecado como algo estructural, como un sistema pecaminoso, como un atolladero del cual no hay salida. La única salida es la intervención de otra lógica que oriente la mente y las prácticas. Se trata de otra justicia diferente, independientemente de la ley. Él la llama justicia de Dios (3.12), que es la justicia de la fe o la justicia de la gracia. Propone una nueva creación que exige morir al pecado (al sistema pecaminoso) y orientar la vida no siguiendo las exigencias de la ley absorbida por el pecado, sino la lógica de la gracia, donde prima la misericordia y el discernimiento que favorece la vida de las personas. En esta otra manera de vivir la ley, las instituciones, las tradiciones, toda lógica de ley estaría al servicio de la vida y no al revés. La promesa paulina es que, con la revelación de la justicia de Dios, mostrada a través del rostro humano de Dios, que es Jesucristo, se da la liberación de la ley, del pecado y de la muerte (Rom. 8, 2), por lo tanto, ninguna condenación pesaría sobre quienes se orientan por la fe o la gracia: ni la espada, ni el hambre (Rom. 8, 34-35). Esto sería para Pablo el llamado a una fe que opera a través del amor (Gál. 5, 6) y a una nueva creación (Gál 6, 15). En concreto, la invitación entonces no es a frenar la avaricia, sino a salir de la lógica que produce la codicia sin límites. Esto implica cambiar radicalmente el orden económico basado en el lucro, a otro solidario basado en la satisfacción de las necesidades de todos.

Los economistas progresistas proponen frenar la codicia del sector financiero y poner controles rígidos al mercado para evitar las crisis y cerrar la brecha de la desigualdad ${ }^{27}$. Los economistas radicales van más en la línea de Pablo, proponen otro

27 Stiglitz piensa que con la aplicación de políticas se pueden reformular las fuerzas del mercado en dirección hacia la igualdad. Pero reconoce que: "No se trata de eliminar 


\section{SIWÔ ' Volumen 10, Números 1, 2016}

orden económico solidario orientado no hacia la ganancia y al consumo sin límites sino hacia la producción de las necesidades fundamentales, las cuales incluyen por supuesto el placer y lo lúdico. Para los economistas neoliberales esto es una locura imposible, pero para la teología esta sería la locura de creer en la resurrección de los muertos. La tarea de estudiosos de la teología es siempre dar esperanza aun en cosas imposibles. La plegaria de los pobres es: "cordero de Dios que quitas el pecado del mundo, danos hoy tu paz".

Desde mi punto de vista estamos viviendo una crisis de civilización, una crisis de humanidad. No es una situación que debe preocupar solo a los afectados. El problema de la pobreza y la escandalosa desigualdad social es un problema de todos. Vivimos en un mundo globalizado y lo que afecta a un sector afecta a otro. No hay posibilidad de mirar a otra parte porque no hay "otra parte", como dice el teólogo español José María Mardones: "Tenemos que mirar a nuestro mundo entero para comprender lo que pasa y lo que nos pasa". Hablar del "otro" es hablar de "nosotros" 28 .

la desigualdad, ni de crear una plena igualdad de oportunidades. Simplemente se trata de reducir una y aumentar la otra". El precio... p. 253.

28 Recuperar la justicia. Religión y política en una sociedad laica (Santander: Sal Terrae, 2005) p. 122. 